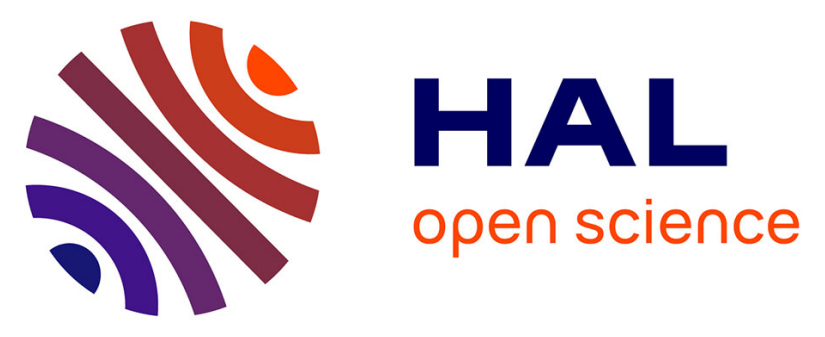

\title{
Cell Based Associations: A procedure for considering scarce and mixed mineral occurrences in predictive mapping
}

Bruno Tourlière, Evren Pakyuz-Charrier, Daniel Cassard, Luc Barbanson, Charles Gumiaux

\section{To cite this version:}

Bruno Tourlière, Evren Pakyuz-Charrier, Daniel Cassard, Luc Barbanson, Charles Gumiaux. Cell Based Associations: A procedure for considering scarce and mixed mineral occurrences in predictive mapping. Computers \& Geosciences, 2015, 78, pp.53-62. 10.1016/j.cageo.2015.01.012 . insu01164639

\section{HAL Id: insu-01164639 \\ https://hal-insu.archives-ouvertes.fr/insu-01164639}

Submitted on 18 Jun 2015

HAL is a multi-disciplinary open access archive for the deposit and dissemination of scientific research documents, whether they are published or not. The documents may come from teaching and research institutions in France or abroad, or from public or private research centers.
L'archive ouverte pluridisciplinaire HAL, est destinée au dépôt et à la diffusion de documents scientifiques de niveau recherche, publiés ou non, émanant des établissements d'enseignement et de recherche français ou étrangers, des laboratoires publics ou privés. 
1 Cell Based Associations, a PRocedure for considering scarce AND MiXed MINERAL OCCURRENCES IN PREDICTIVE MAPPING

3 Bruno Tourlière ${ }^{* 1}$, Evren Pakyuz-Charrier ${ }^{2}$, Daniel Cassard ${ }^{1}$, Luc Barbanson ${ }^{3}$ and Charles 4 Gumiaux $^{3}$

.

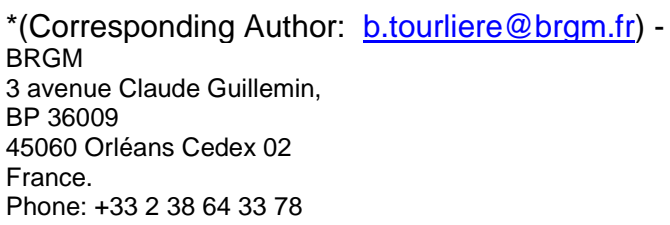

(1)

Cell Based Association is an innovative mineral favorability procedure designed to answer special needs of the mining industry in data wise critical situations where usual favorability methods may not yield satisfactory results. Those situations relate to input data quality (e.g.: clustered points, mixed and scarce data, approximate location) or some assumptions that are considered unreasonable (e.g.: map areas relevance, conditional independence).

The principle of CBA consists in replacing polygons of geological units with a square cell grid (hence the 'cell-based'). Each cell contains a range of units ('association') that are binary coded in terms of their presence (1) or absence (0) within study area. The loss of resolution inherent to this procedure is compensated by the enriched information contained in each cell owing to the notion of (lithological) association.

Lithological associations are considered as binary spectra and as such are classified using Ascendant Hierarchical Clustering $(\mathrm{AHC})$ thus obtaining a synthetic map of lithological associations. The prospectivity map shows as favorable the cells of the same AHC classes that the ones including mineral occurrences.

It was observed that CBA can distinguish between different ore deposit varieties from a blended mineral occurrences data set. CBA can theoretically include any spatialized data (e.g.: geophysics, 
structural data) as an extra variable to specify classification and narrow favourable areas. Doing so would make it an independent favorability mapping procedure and is still under development. 


\section{Introduction}

Mineral favorability is a branch of predictive analytics that focuses on designing statistical methods to point out favourable zones in terms of mining potential.

From Carranza (2009) : "The term mineral prospectivity (...) is similar to the terms mineral potential and mineral favourability, both of which imply the chance or likelihood that mineral deposits of the type sought are contained in a region or district under investigation. (...)

Modeling of mineral prospectivity is a regional- or district scale mapping activity, whether field based or GIS based, which aims to delineate prospective areas for further exploration at the next higher scales of mapping. Notwithstanding the scale of mapping, mineral prospectivity is related to the degrees of presence and degrees of importance of individual pieces of spatial evidence of occurrence of mineral deposits of the type sought. That is, in a region or district under investigation, if there are more important pieces of spatial evidence in an area than in another area, then the former is considered to have higher prospectivity than the latter".

The most basic case relates to measuring the statistical link between a mineral occurrence (MO) data set (points) and a geological map (polygons). This can roughly be translated as finding what makes places where mineral occurrences were observed distinguishable and trying to target similar locations.

End result is often a favorability map that displays the odds of finding something of interest.

Cell Based Association (CBA) is meant to be used during the strategic stages of exploration when available data often does not meet the requirements (independence, representativeness of $\mathrm{MO}$ ) of usual favorability methods such as Weight of Evidence, Fuzzy Logic, Artificial Neural Networks to be used effectively (Bonham-Carter, 1984, Carranza, 2011, Schaeben, 2011)).

Usually the requirements are not met due to poor quality of the mineral occurrence data set. Indeed, the mineral occurrence data set is normally considered as a unique representative sample of unique elements of a single population (or at least a known number of different populations). This is not always the case as mineral occurrences data sets are most of the time classified according to the (potential) resource observed (e.g.: zinc mineral occurrences) which can lead to mixing different types of mineral occurrences that relate to different genesis processes (hence 
different lithological environments) into a single mineral occurrence data set. Ultimately this means the user will obtain a mixed favorability map that, at best, roughly ranks the different types of mineral occurrences on a single scale that may make no sense because each type should be analysed separately from the others or, at worst, a global fuzzy favorability map that makes even less sense.

Also, when the mineral occurrences data set is too scarce it is impossible to assess if it is representative which is one major assumption/requirement of most favorability methods.

Lastly, considering each mineral occurrence as individual leads to an overestimate of the importance of clustered areas that in fact describe a single object geologically wise which is even more critical in the case of mixed mineral occurrence data sets.

To address these problems, we propose a procedure called 'Cell-Based Associations' (CBA). Using a square grid (of appropriate cell size fixed by user) in which each cell records the presence or absence of lithological units from the geological map and a hybrid driven (combining data and user driven approaches) classification of all cells, this procedure allows to generate a synthetic map that can be coupled to the mineral occurrence data set. CBA thus allows better characterization and sorting of a number of different complex environments associated with the looked for phenomena.

A technique consisting in applying a grid with included attributes over a study area was previously described by McCammon et al. (1983) for generating predictive maps, but rather than using their Characteristic Analysis method of data processing of a logical type, CBA uses statistical ranking of coded cells for identifying the different associations/environments contained in the map.

\section{The principles of CBA}

The case study presented here in for illustrating the principles of the CBA procedure is a mapping of mineral favorability, where the points are mineralized occurrences (MO) and the polygons are geological units (lithologies). The artificial map in Figure 1 shows the type of document used by geologists when looking for prospective areas that are a-priori favourable to the presence of mineralization. On this map, mineral occurrences are present in the $B, D$ and $E$ units. Occurrence 
"OCC-4" is located in unit C, but its position very close to the limit between units $E$ and $D$ might be imprecise.

The CBA procedure was applied to that dataset. First, the optimal cell size of the grid had to be defined. This size relies on two main constraints: 1) it should be coherent with the size of the studied phenomena (Carranza, 2009), and 2) it must allow a sufficient variability of the geological units. Too small cells will contain only one unit, but too large ones will contain too many (if not all) units.

The relationship between the variability inside the grid cell and its size has been studied in the dataset in order to define the optimized size for a cell. Variability has been estimated using 2 parameters: the average number of geological units per cell and the number of lithological spectra (or associations, see definition below) generated by the 'cut-out' of the map by grids with different cell sizes (Table 1). The graphic representation (Figure 2) of this result shows that the optimal size of a cell ranges from 7 to $12 \mathrm{~km}$ (side length of square cells), which corresponds to a number of spectra comprised between 15 and 17 (for a theoretical maximum of 36 [i.e. $2^{5}$ ] possible combinations, 17 being the maximum number of combinations present in the map) and an average number of lithologies per cell ranging from 1.8 to 2.2 (Table 1). In this example, the cell size was arbitrarily set at $10 \mathrm{~km}$ that is between 7 and $12 \mathrm{~km}$.

Once the cell size has been defined by user, the grid is generated and superimposed on the geological map (Figure 3). All cells have for attributes all the units represented in the map. The geological information contained in each cell is coded as presence $=1$ or absence $=0$ of each geological contained in the map (Figure 4 and Table 2). Each cell is then characterized by a binary-type attribute spectrum showing the presence/absence of each unit within it.There is thus a transition from a discrete categorical variable (rock type) to a set of binary variables describing a lithological spectrum or - more generally - an attribute spectrum. This operation does not consider the relative or absolute surface of the geological units, but only their presence or absence. This reasoning is based on the idea that the projected surface of a unit on a geological map is irrelevant for determining its real importance as a small area unit may be the critical factor that determines a particular lithological environment (e.g.: dyke fields) or may be the end of a much larger body (e.g.: plutonic intrusion) it also may be partially masked surficial deposits. It seems preferable to 
emphasize the presence of poorly represented units than to lose that information because mining favorability is ultimately a $3 D$ problem. The processing of each unit as an independent binary variable assumes that a geological map is a combination of exclusive events, in other words: at every location of the map a single lithology may be observed.

This technique avoids the loss of attribute information (Bai et al., 2011) and renders it directly usable for multivariate analysis. The maximum number of possible combinations is $2^{n}$, where $n$ is the number of attributes, here geological units. If the number of attributes is large, the individual processing of all present combinations becomes impossible, implying the need to use a method that allows grouping the attribute spectra into representative classes of existing combinations.

Same processing should have been possible in raster mode but that implies a multiplication of layers (one per unit) and a possible loss of information for small surface covering units. The creation of a single table containing all the attributes is less time consuming, makes it easier to treat and is coherent with the notion of spectrum created by concatenation of the attributes.

In the present work, the hybrid driven Ascendant Hierarchical Clustering ( $\mathrm{AHC}$ ) method has been used to classify the associations within the cells.

\section{The principles of AHC}

AHC uses a system of aggregation by pairs of elements according to: 1) their proximity based on a dissimilarity function that measures the multivariate statistical distance between the elements; and 2) an aggregation function that groups those that are iteratively the closest (Rolet and Seguin, 1986)

In the present case, the calculation relies on a dissimilarity index based on "percent disagreement" (Equation 1) and an aggregation function based on the reciprocal neighbours method (Rham, 1980) after centring and reduction of the data.

The dissimilarity index is as follows:

$$
d P\left(I_{i}, I_{j}\right)=\frac{\text { number of }\left(x_{i k} \neq x_{j k}\right)}{K}
$$

Where $\mathrm{i}$ and $\mathrm{j}$ are the identifiers of the compared elements $\mathrm{I}, \mathrm{k}$ is the variable (geological unit) identifier, $x$ is the variable value, and $\mathrm{K}$ the number of variables (number of units). This type of 
dissimilarity function is used for variables of the categorical/discrete type, and is the most suitable for evaluating the distance between elements.

However, in our specific case it is also possible to use the usual Euclidean distance (Equation 2) as it is easier to apply instead of the dissimilarity function.

$$
d E\left(I_{i}, I_{j}\right)=\sqrt{\sum_{k}\left(x_{i k}-x_{j k}\right)^{2}}
$$

For this, equations 3.1 to 3.2 are used. As $x$ can only take the values 0 or 1 , we have:

$$
\sqrt{\sum_{k}\left(x_{i k}-x_{j k}\right)^{2}}=\text { number } \text { of }\left(x_{i k} \neq x_{j k}\right) \forall x=\{0,1\}
$$

Where

$$
d E\left(I_{i}, I_{j}\right)=d P\left(I_{i}, I_{j}\right) * K \forall x=\{0,1\}
$$

Where $i$ and $j$ are the identifiers of the compared elements I (cells), $k$ the variable (unit) identifier, $x$ the value of the variable, and $\mathrm{K}$ the number of variables (units).

The choice of Euclidian distance is arbitrary as it is the most "intuitive" but other kind of distance could be used as Manhattan distance for example. The aggregation factor for classes is minimum in-class variance. Varying those parameters could lead to significantly different results in classification that have not been tested.

$\mathrm{AHC}$ produces a binary hierarchical grouping of the attributes characterizing each element in a class. The quality of such grouping progressively degrades with a diminishing number of classes (Hastie et al., 2009). This is generally expressed as a dendrogram (Figure 5) showing intermediate grouping results and their hierarchical relations, which allows to select the number of classes to represent lithological environments. That number of classes is based on the morphology of the dendrogram and has to be balanced by the user between a low level of aggregation (numerous classes) that will give a fine description of lithological associations with the risk to describe very local associations and a high level of aggregation (few classes) that will be too comprehensive and thus not applicable to the searched result. Once the level of cutting chosen by the user, an attribute is added to the table to store the AHC class attribute (Table 3 ) in order to mark the classes attributed to each cell, each class corresponding to a group of associated units. 
It is also possible to calculate classification quality for each cell and each level. This quality criteria corresponds to the Euclidean distance between the cell and the barycentre of the class to which the cell belongs. The quality value associated with each cell ('Qual' columns in Table 3) thus shows the strength of the link between the cell and its attributed class. This parameter ideally should be 0 , but this is conceptually impossible when grouping the lithological associations by using $\mathrm{AHC}$. This quality parameter is useful for comparing different classification levels (number of classes) of the same dataset.

\section{Results}

Figure 6 shows a cartographic plot of classes and thematic analysis for a 10 class cut-off of the dendrogram.

Cells of the same class do not exactly present the same lithological spectrum. This is the case, for instance, for the four cells of class 7 (no filling) from which 2 are of type 00110 and 2 of type 00111. The grouping of class 7 was thus based on a common spectrum of type $0011 \mathrm{x}(\mathrm{x}$ being 1 or 0 ). Class 5 (horizontal and vertical cross-hatching) shows a similar case with a spectrum of the $01 \times 11$ type and class 10 (left inclined wide-spaced hatching) with a spectrum of the $1 \times 101$ type. This clearly illustrates that classification quality decreases along with the number of classes. Nevertheless, the fundamental characteristics of the associations forming the classes are conserved.

Producing the favorability map (Figure 7) consists in (i) selecting the classes of the cells that contain occurrences, and (ii) extracting all the cells showing one of the favourable classes. In this example, cells of class 6 (association of units D and E), 7 (units C, D and E) and 8 (units C and D) are associated to mineral occurrences and are, thus corresponding to geological environments favourable for the presence of mineralisation. In this example, other classes do not contain any occurrence and are thus considered as non-favourable 
The CBA procedure goes counter to the natural tendency of trying to obtain the finest possible resolution. CBA, on the contrary, aims to define an association of elementary signatures present in a larger area, rather than looking for the smallest elementary signature possible. This led to the idea of considering a larger cell that integrates an environment defined as the presence or absence of all lithological units in the study area.

Moreover, this type of approach mimics the thought process of geoscientists as it associates phenomena with a multifactorial context rather than a single criterion. In mineral exploration, for instance, the exploration geologist will favour a complex geological setting over a single unit (e.g. Billa et al., 2004; Roy et al., 2006; Cassard et al., 2008).

Cell size is a critical parameter to the procedure and must comply with two major constrains: coherence with the size of the phenomena of interest (Carranza, 2009), and sufficient variability of the attributes per cell. For correct operation of the procedure, the cells should neither be too small mineral occurrence data set. also is the cell size parameter that allows CBA to deal with over and under sampling issues of the

As discussed in section 2, given that the MO display minute to no clustering effect, a grid of suitably-sized meshes can be calculated, based on the variability of the lithology parameter estimated either on the average number of unit contained in grid cells or on the number of unique lithological associations 'generated' by this grid. Conversely, statistics based on MO spatial behaviour (i.e. "kernel density method for univariate data" (Silverman,1986) or "pair correlation function $g(r) "$ (Van Leeuwen et al, 1959) ) may be used as indicators to optimize cell size provided that they allow for sufficient variability of the units in the cells. As a last resort, the size of the cells is a decision of the user who must reconcile a size compatible with the map(s) scale and the searched for events. CBA, as described in this paper, is based on a regular grid, but it will work just as well with cells of variable size adapted to the influence of the units, so as to limit the number of mono-attribute cells. 
The idea of 'specific surface' of a unit, whether by cell or within the study area, was considered as irrelevant as this is a variable induced by the intersection between topography and units that may be partly covered by overlapping units. It is supposed that the area of a mapped unit is not a critical criterion and that mineral deposits are likely to be linked to "rare" units as much as more frequent ones. This is why only existence is taken into account ( 0 or 1$)$ which in return favours presence over absence: it highlights details over global trends because we consider that only the proximity to observed MO is important in this case.

CBA uses positive reasoning assuming that "non-links" are impossible to demonstrate. In reality, it is impossible to conclude that the absence of a certain unit reduces the odds of finding a MO. Geological maps and geologists observation are never perfect and, having no $\mathrm{MO}$ in a certain lithological setting does not make it unfavourable, it makes it non-favourable. As such, positive reasoning (observations lead to consider the environment in which they are found as favourable) should be preferred over negative reasoning (environments in which no observation are found are unfavourable). Ultimately, this relates to the way field geologists work, describing the environment where the presence of MO proves that it is a favourable one, whatever are the respective surfaces of the units on the geological map. be introduced as the respective percentage covered by each attribute in the cell, with 0 indicating its absence. This type of approach has not yet been tested but could be an interesting development of this work.

For cell ranking, the Ascendant Hierarchical Clustering (AHC) has been selected because, in addition to being a hybrid driven classification function, it produces a hierarchical tree (dendrogram) that shows the relations between the different classes. The number of classes is a user decision helped by the shape of the branches of the dendrogram and the level of details he requires. Based on the cut-off level (i.e., the number of classes) of the tree, the classes will be more or less informative, thus more or less focused on relevant lithological spectrum. For rather low cut-off levels (i.e., few classes), AHC commonly produces a "garbage" class that covers all cells poorly classified for this level. In the case of several occurrences falling within this class, it is however always possible to extract the related cells for an independent re-classification. 
Other methods of multivariate classifications - as, for example, IsoData, K-means clustering - may yield different results. They are still to be tried.

The result obtained from such data processing is a new synthetic map of the assemblage of classified cells showing the different groups of associations in the study area.

Family of cells containing MO will be regarded as favourable and the capability of the procedure to describe the contained association of lithologies is helpful for exploration teams to point out the cells showing the same environment than the ones with MO. Even in that case, results must be interpreted to check their relevance.

CBA can induce a bias for points located near a cell boundary that might correspond to a different lithological spectrum from that effectively favourable. This drawback is limited if the number of occurrences is sufficiently large. However, if too many showings lie close to cell boundaries, it may be necessary to shift the grid origin or change the cell size (Pakyuz-Charrier, 2013).

According to points presented and discussed here above, predictive results of the CBA procedure could possibly be further improved by:

- Ignoring specific units (such as alluvium) that clearly are irrelevant to the phenomenon looked for. Classification will then be based on a partial lithological spectrum, which might improve the quality of the result.

- Introducing relevant parameters into the cells that come from other thematic layers, such as the presence/absence of faults or geophysical anomalies. Such additional attributes enrich the information contained in the spectrum and can be used for classification, which then becomes multi-thematic. The approach would then shift from a "bivariate-data driven" to a "multivariate-data driven" method (Carranza, 2011) that resembles McCammon's "characteristic analysis" (1983).

- Producing more relevant classes by using other classification methods.

In supervised mode, CBA can be used by processing only cells that contain occurrences, provided they are sufficiently numerous for statistical processing. In this case, only the lithological spectra associated to mineralization would be classified. A predictive map would then be produced by selecting all cells with comparable spectra to those deriving from the classification. This 
approach (Cassard et al., 2012; Tourlière et al., 2012) is not illustrated here. In simple cases, it may allow dispensing with classification, becoming comparable to the "characteristic analysis" approach (McCammon, 1983).

In addition the synthetic map produced by spectra classification with the CBA procedure can help in (i) interpreting a thematic map and (ii) highlighting the presence of distant but similar association areas.

\section{Conclusions}

The Cell-Based Associations (CBA) procedure was developed for overcoming the limitations caused by low quality input data sets often used in early stages of mining exploration.

Application of a cell grid ('cell based') of suitable size (fixed by the user) over a study area and the coding of the units found in each cell as 1 (presence) or 0 (absence), allows obtaining a binary attribute spectrum ('association) that can be statistically classified.

Decrease in resolution of the original data induced by the procedure is compensated by the concept of association that, after classification, allows the extraction and regrouping of more complex environments and their cartography as a synthetic map.

This approach better considers the complexity of geological phenomena favouring the presence of mineralization and is able to distinguish different types of favourable lithological environments. It is also possible to integrate data from other thematic layers (e.g., tectonic structures, geophysical properties...) into the cells which enriches the attribute spectrum, thus opens the possibility of creating multi-thematic synthetic maps.

As presented in that paper, CBA can be a guide to mining exploration essentially at strategic scale when the mining occurrences are scarce or clustered and units areas are irrelevant or small areas are suspected to be important.

The hybrid driven statistical method (Ascendant Hierarchical Clustering) has been used in this study for calculating the grouping of geological environments by cell but other methods of classification can be relevant too. CBA can also be used as a dataset for predictive methods of the supervised type by using cells containing showings as learning sets. 
328 Apart from any search for predictions the CBA procedure produces a synthetic thematic 329 representation that may help in the interpretation of complex and/or very large scale maps.

330

\section{Acknowledgements}

This work was initiated as part of the EU-FP7 funded "ProMine" project (grant agreement $\mathrm{n}^{\circ}$ 228559) and finalized in the frame of the "Favorability" project of BRGM's "RSM 16" Scientific Programme.

Many thanks to the two anonymous reviewers who guided us into redirecting this paper to make it more relevant. 


\section{References}

Bai, Y., Liao, S., Jiulin, S., 2011. Scale effect and methods for accuracy evaluation of attribute information loss in rasterization. Geographical Science, pp. 1089-1100.

Billa M., Cassard D., Lips A.L.W., Bouchot V., Tourlière B., Stein G. and Guillou-Frottier L., 2004. Predicting gold-rich epithermal and porphyry systems in the central Andes with a continental-scale metallogenic GIS. Ore Geology Reviews, 25, pp. 39-67.

Bonham-Carter, G.F., 1994. Geographic Information Systems for Geoscientists: Modelling with GIS: Pergamon, Oxford, $398 \mathrm{pp}$.

Carranza, E.J.M., 2009. Objective selection of suitable unit cellsize in data-driven modeling of mineral prospectivity: Computers \& Geosciences 35, pp. 2032-2046.

Carranza, E.J.M., 2011. Geocomputation of mineral exploration targets. Computers \& Geosciences 37, pp. 1907-1916.

Cassard D., Bertrand G., Monthel J., Gloaguen E., Melleton J., Husson Y., Billa M. et Tourlière B., 2012. Réévaluation du potentiel français en ressources minérales : élaboration d'une méthodologie et application à une zone d'étude test (sud-ouest du Massif central). Final report. BRGM/RP61745-FR, 126 p. Public document in French downloadable at: HYPERLINK "http://infoterre.brgm.fr/rapports/RP-61745-FR.pdf" http://infoterre.brgm.fr/rapports/RP-61745FR.pdf

Cassard D., Billa M., Lambert A., Picot J.-C., Husson Y., Lasserre J.-L., Delor C., 2008. Gold predictivity mapping in French Guiana using an expert-guided data-driven approach based on a regional-scale GIS. Ore Geology Reviews, 34, pp. 471-500.

Hastie, T., Tibshirani, R., Friedman, J., 2009. The Elements of Statistical Learning: Data Mining, Inference, and Prediction. Stanford: Springer.

McCammon R.B., Botbol J.M., Sinding-Larsen R., Bowen R.W., 1983 HYPERLINK "https://www.researchgate.net/publication/226193164_Characteristic_analysis1981_Final_program _and_a_possible_discovery?ev=prf_pub" . Characteristic Analysis-1981: Final Program and a Possible Discovery. Mathematical Geology 15(1), pp.59-83.

Pakyuz-Charrier E., 2013. Cell Based Associations: An alternative to Weight of Evidence using cell based lithological associations. PhD Thesis Univ. Orleans, 63 pp.

Rham, C. D., 1980. La classification ascendante hiérarchique ascendante selon la méthode des voisins réciproques. In Les cahiers de l'analyse des données, pp. 135-144. Dunod.

Rolet, P., Seguin, J.J., 1986a. Traitement de donnees multivariables (Application aux sciences de la Terre) Approche theorique, Tome 1 - Version 1.0. BRGM Report BRGM/86-DT-005-ISA, 120 pp. Public document in French downloadable at: HYPERLINK "http://infoterre.brgm.fr/rapports/86-DT005-ISA.pdf" http://infoterre.brgm.fr/rapports/86-DT-005-ISA.pdf

Rolet, P., Seguin, J.J., 1986b. Traitement de donnees multivariables (Application aux sciences de la Terre) Aspect pratique, Tome2 - Version 1.0. BRGM Report BRGM/86-DT-006-ISA, 62pp Public document in French downloadable at: HYPERLINK "http://infoterre.brgm.fr/rapports/86-DT-006ISA.pdf" http://infoterre.brgm.fr/rapports/86-DT-006-ISA.pdf

Roy R., Cassard D., Cobbold P.R., Rossello E.A., Billa M., Bailly L. and Lips A.L.W., 2006. Predictive mapping for copper-gold magmatic-hydrothermal systems in NW Argentina: use of a regional-scale GIS, application of an expert-guided data-driven approach, and comparison with results from a continental-scale GIS. Ore Geology Reviews, 29, pp. 260-286.

Schaeben, H., 2011. Comparison of Mathematical Methods of Potential Modeling. Mathematical Geoscience, pp. 101-129.

Silverman, B. W. (1986). Density estimation for statistics and data analysis, Monographs on Statistics and Applied Probability, London: Chapman and Hall/CRC. pp. 7-11

Van Leeuwen, J. M. J., Groeneveld, J., De Boer, J. (1959). New Method for the Calculation of the Pair Correlation Function. Physica, 25: pp. 792-208

Mis en forme : Anglais (États Unis)

Mis en forme : Espagno (International) 
Figures :

392 Figure 1: Geological map and mineral occurrences (theoretical example)

393 Figure 2: Optimal cell size range estimated by the number of different spectra generated by the 394 gridding

395 Figure 3: Grid mesh of 10km applied to the geological map of Figure 1 and numbering of cells

396 Figure 4: Grid applied to the geological map of Figure 1 and binary coding of the lithological spectra of cels

398 Figure 5: Dendrogram of lithological associations; data are those of Figure 4; dotted lines indicate 399 cut-offs according to the desired number of classes (15 10, 7 and 5 classes)

400 Figure 6: Result of cell classification with AHC in the case of a cut-off at 10 classes. The binary 401 series correspond to the lithological spectra of the different cells (Figure 4)

402 Figure 7: Favorability map: cells of the same class as those containing occurrences, bold numbers indicating the class of association.

Tables:

Table 1: Relationships between the cell size and lithological variability. Grey area = optimal cell size range.

408 Table 2: Attributes of the grid after extracting the lithological information. For each cell (line) a 409 lithological spectrum is defined by the presence/absence of all lithologies on the map (columns)

410 Table 3: Attributes of the grid after AHC. The different AHC columns correspond to different cut-off 411 levels in the dendrogram. Whole numbers correspond to the lithological association for a given cell 412 and for a set cut-off level (see Figure 5). 'Qual' measures the quality of each cell in terms of the dissimilarity between it and the multivariate centre of gravity of the class comprising the cell 


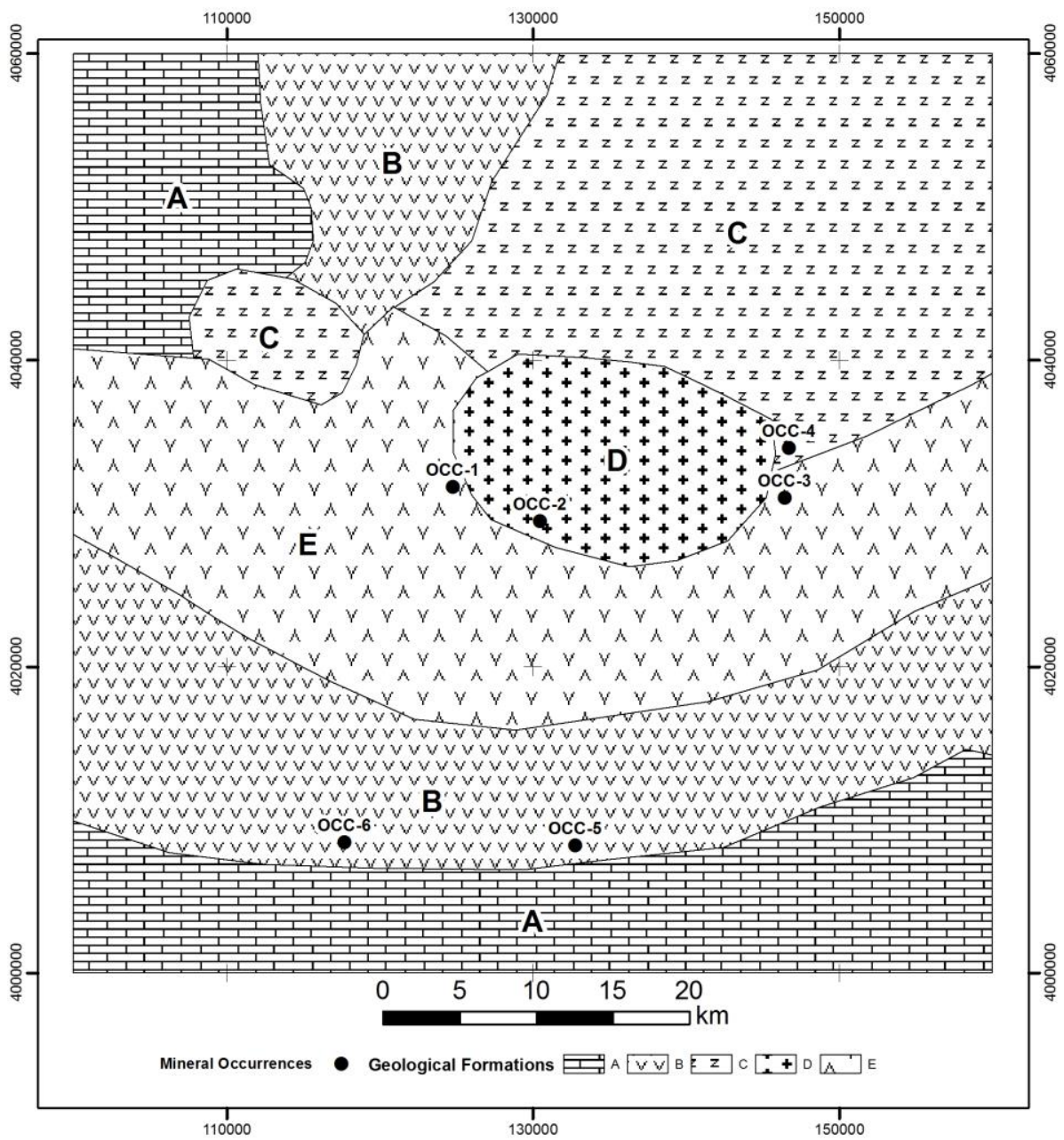




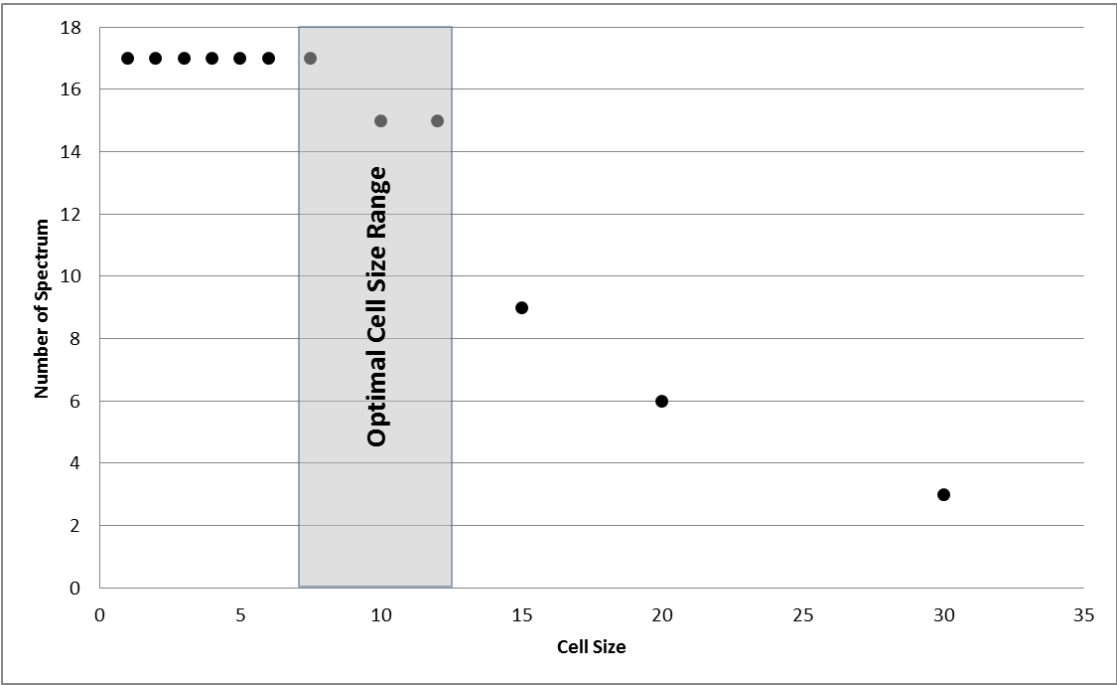

428 Figure 2: Optimal cell size range estimated by the number of different spectra generated by the gridding 


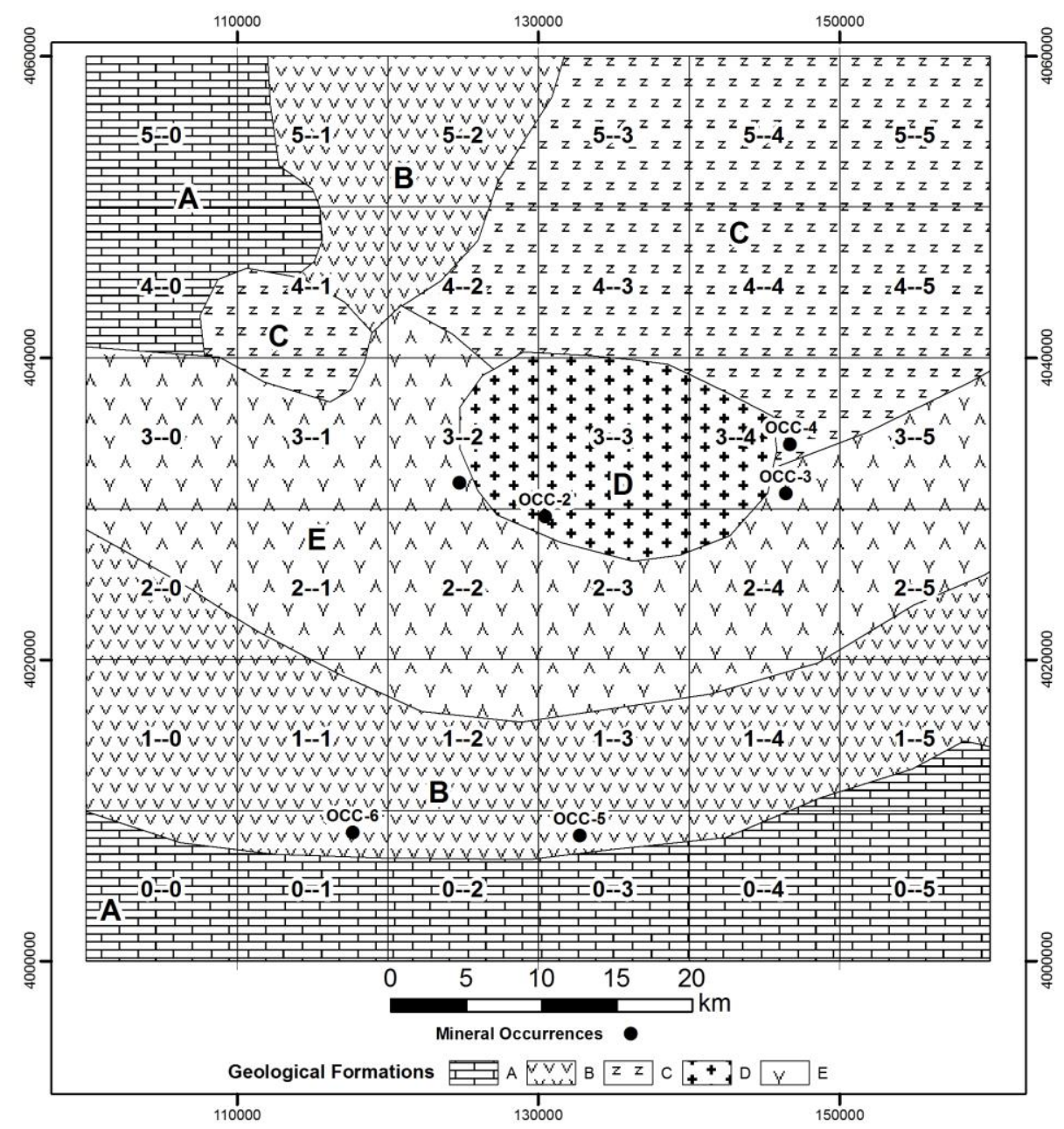

430

Figure 3: Grid mesh of $10 \mathrm{~km}$ applied to the geological map of Figure 1 and numbering of cells 


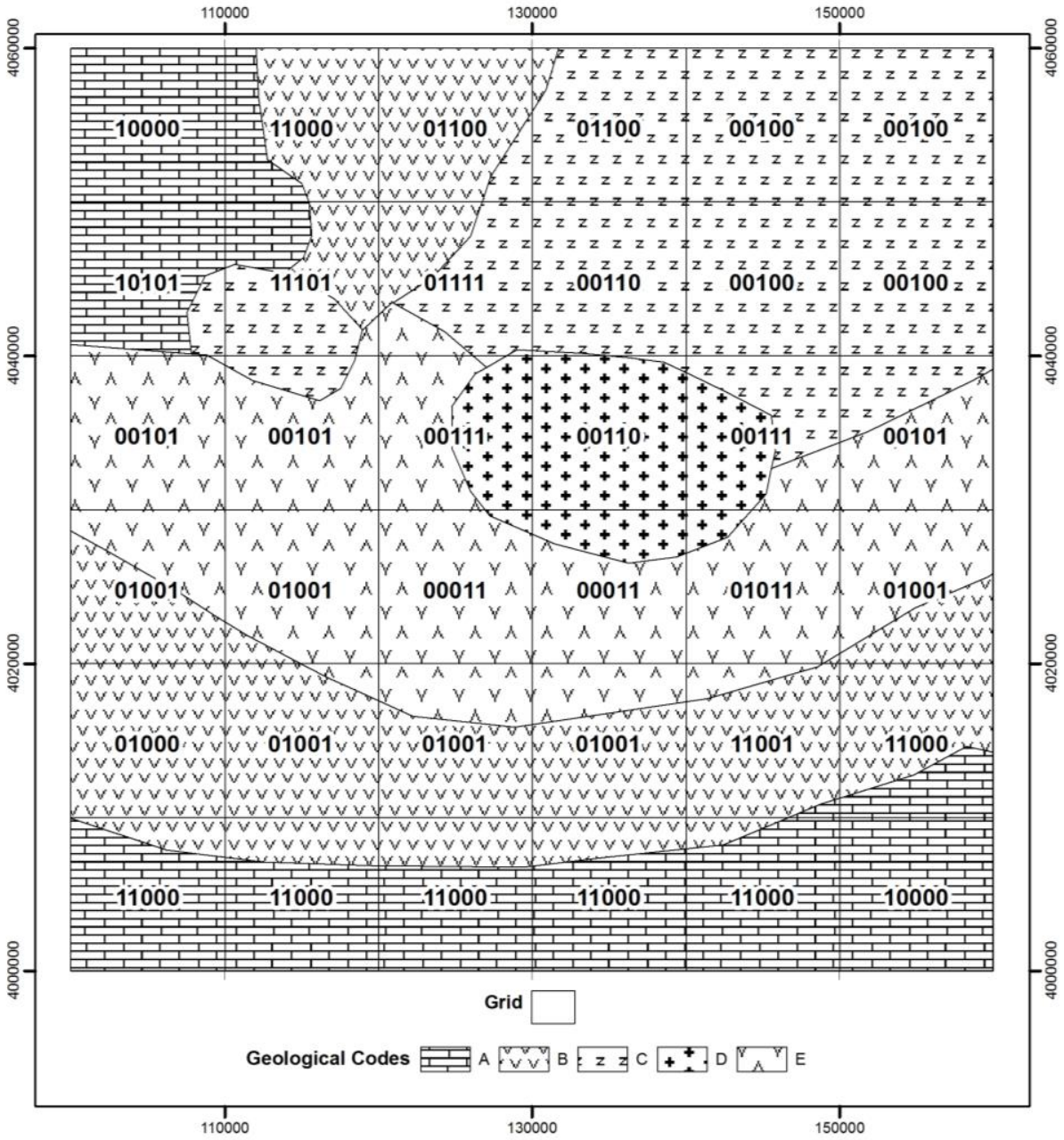

Figure 4: Grid applied to the geological map of Figure 1 and binary coding of the lithological spectra of cells 


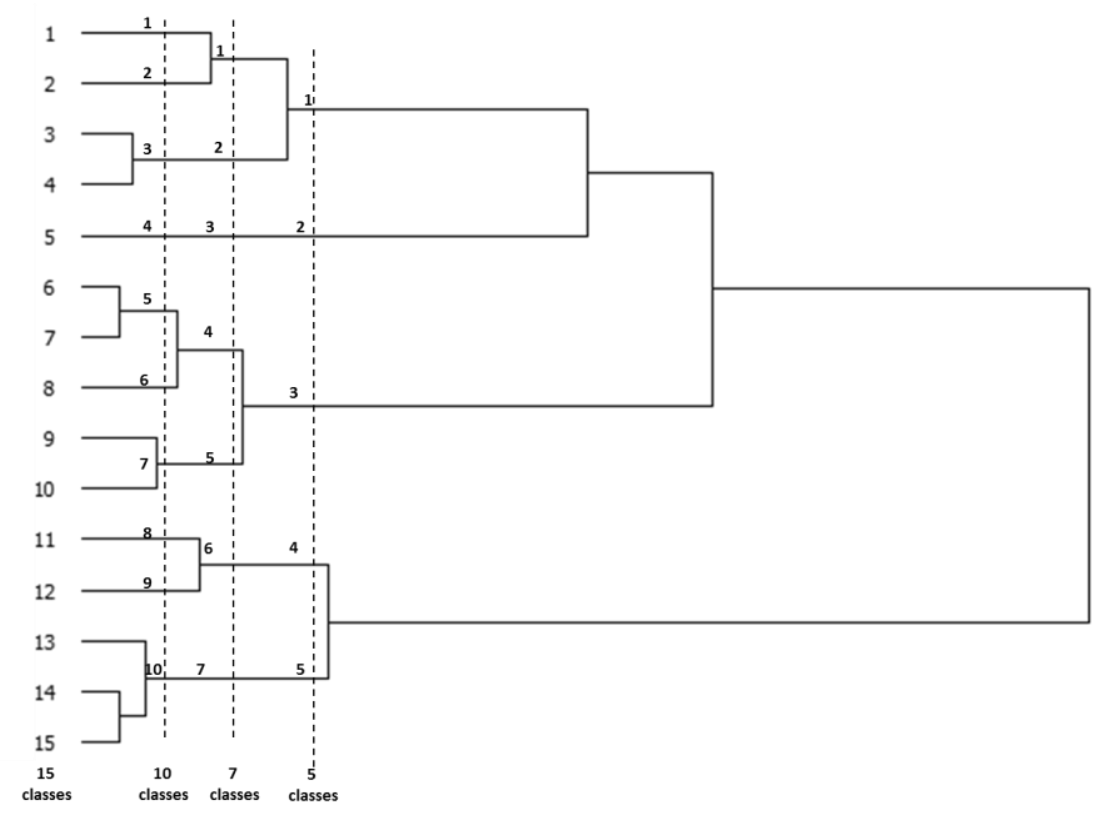

Figure 5: Dendrogram of lithological associations; data are those of Figure 4; dotted lines indicate cut-offs according to the desired number of classes $(15,10,7$ and 5 classes) 


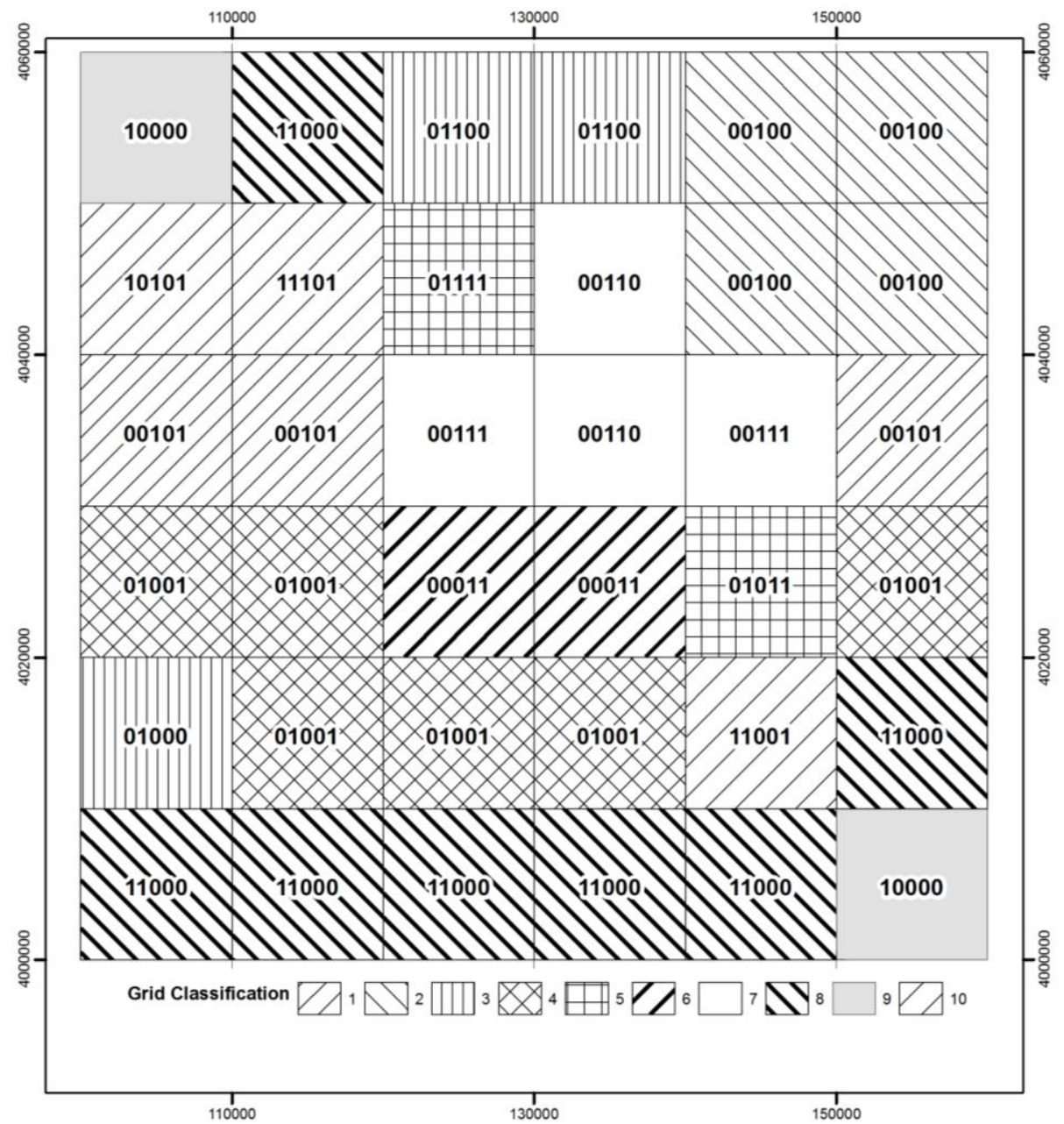

Figure 6: Result of cell classification with AHC in the case of a cut-off at 10 classes. The binary series correspond to the lithological spectra of the different cells (Figure 4) 


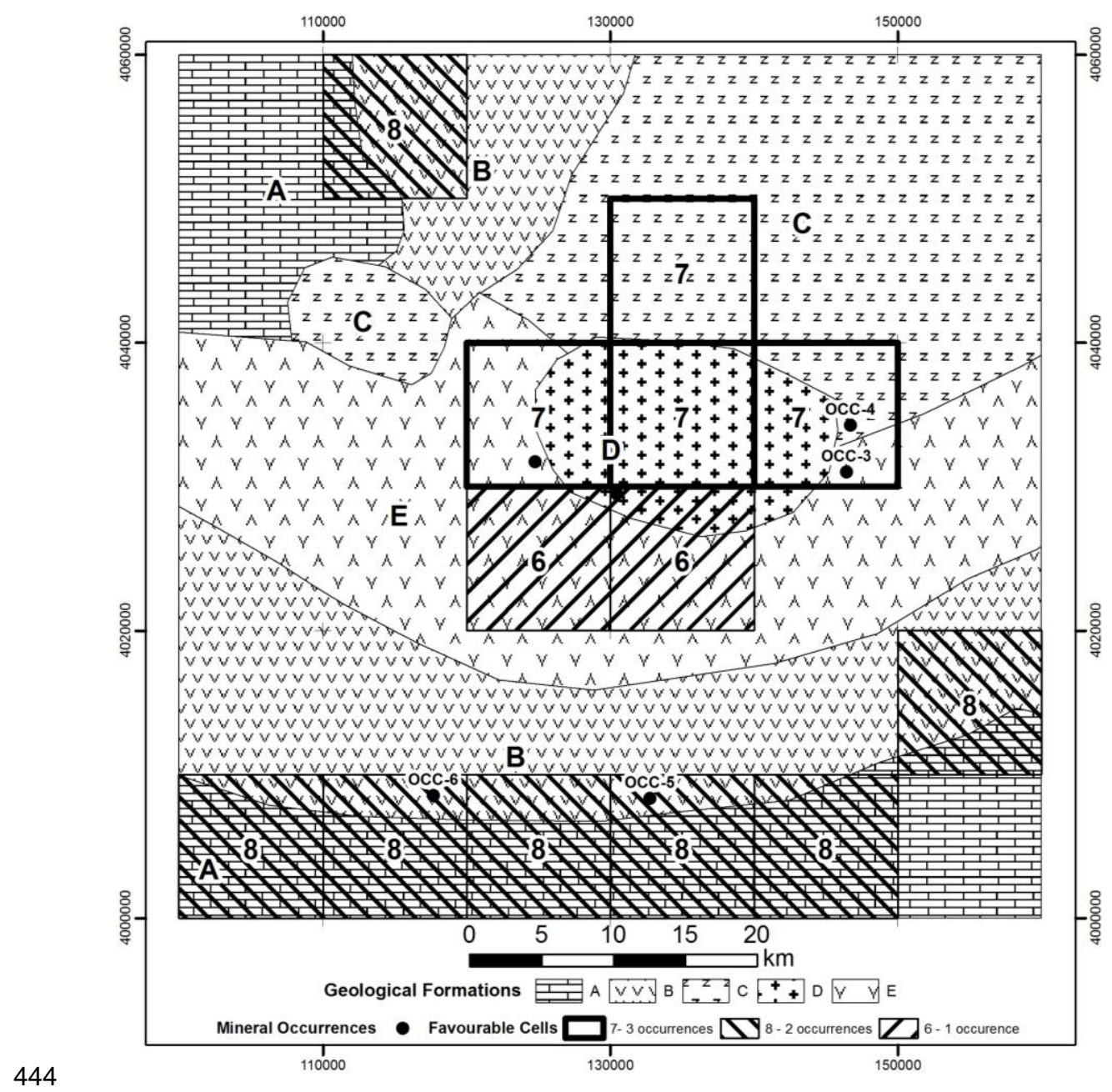

445

446

447

448

449

450

451

Figure 7: Favorability map: cells of the same class as those containing occurrences, bold numbers indicating the class of association. 


\begin{tabular}{|r|r|r|r|r|}
\hline $\begin{array}{c}\text { Number of } \\
\text { cells }\end{array}$ & $\begin{array}{c}\text { Cell size } \\
(\mathrm{km})\end{array}$ & $\begin{array}{c}\text { Average } \\
\text { number of } \\
\text { lithologies } \\
\text { by cell }\end{array}$ & $\begin{array}{c}\text { Number of } \\
\text { Speciific } \\
\text { lithologic } \\
\text { spectra }\end{array}$ & $\begin{array}{c}\text { Number of } \\
\text { cells with } \\
\text { occurrences }\end{array}$ \\
\hline 4 & 30 & 4.25 & 3 & 4 \\
\hline 9 & 20 & 3.11 & 6 & 4 \\
\hline 16 & 15 & 2.56 & 9 & 5 \\
\hline 25 & 12 & 2.16 & 15 & 4 \\
\hline 36 & 10 & 2.06 & 15 & 5 \\
\hline 64 & 7.5 & 1.78 & 17 & 5 \\
\hline 100 & 6 & 1.57 & 17 & 5 \\
\hline 144 & 5 & 1.51 & 17 & 5 \\
\hline 225 & 4 & 1.4 & 17 & 6 \\
\hline 400 & 3 & 1.3 & 17 & 6 \\
\hline 900 & 2 & 1.2 & 17 & 6 \\
\hline 3600 & 1 & 1.1 & 17 & 6 \\
\hline & & & & \\
\hline
\end{tabular}

Table 1: Relationships between the cell size and the lithological variability. Grey area $=$

\begin{tabular}{|c|c|c|c|c|c|c|c|c|c|c|c|c|c|}
\hline \multirow[b]{2}{*}{ Cell\# } & \multicolumn{5}{|c|}{ Formations } & \multirow{2}{*}{$\begin{array}{l}\text { Lithological } \\
\text { Spectrum }\end{array}$} & \multirow[b]{2}{*}{ Cell\# } & \multicolumn{5}{|c|}{ Formations } & \multirow{2}{*}{$\begin{array}{c}\text { Lithological } \\
\text { Spectrum }\end{array}$} \\
\hline & A & B & C & D & $E$ & & & A & B & C & D & $E$ & \\
\hline $0--0$ & 1 & 1 & 0 & 0 & 0 & 11000 & $3--0$ & 0 & 0 & 1 & 0 & 1 & 00101 \\
\hline $0--1$ & 1 & 1 & 0 & 0 & 0 & 11000 & $3--1$ & 0 & 0 & 1 & 0 & 1 & 00101 \\
\hline $0--2$ & 1 & 1 & 0 & 0 & 0 & 11000 & $3--2$ & 0 & 0 & 1 & 1 & 1 & 00111 \\
\hline $0--3$ & 1 & 1 & 0 & 0 & 0 & 11000 & $3--3$ & 0 & 0 & 1 & 1 & 0 & 00110 \\
\hline $0--4$ & 1 & 1 & 0 & 0 & 0 & 11000 & $3--4$ & 0 & 0 & 1 & 1 & 1 & 00111 \\
\hline $0--5$ & 1 & 0 & 0 & 0 & 0 & 10000 & $3--5$ & 0 & 0 & 1 & 0 & 1 & 00101 \\
\hline $1--0$ & 0 & 1 & 0 & 0 & 0 & 01000 & $4--0$ & 1 & 0 & 1 & 0 & 1 & 10101 \\
\hline $1--1$ & 0 & 1 & 0 & 0 & 1 & 01001 & $4--1$ & 1 & 1 & 1 & 0 & 1 & 11101 \\
\hline $1--2$ & 0 & 1 & 0 & 0 & 1 & 01001 & $4--2$ & 0 & 1 & 1 & 1 & 1 & 01111 \\
\hline $1--3$ & 0 & 1 & 0 & 0 & 1 & 01001 & $4--3$ & 0 & 0 & 1 & 1 & 0 & 00110 \\
\hline $1--4$ & 1 & 1 & 0 & 0 & 1 & 11001 & $4--4$ & 0 & 0 & 1 & 0 & 0 & 00100 \\
\hline $1--5$ & 1 & 1 & 0 & 0 & 0 & 11000 & $4--5$ & 0 & 0 & 1 & 0 & 0 & 00100 \\
\hline $2--0$ & 0 & 1 & 0 & 0 & 1 & 01001 & $5--0$ & 1 & 0 & 0 & 0 & 0 & 10000 \\
\hline 2--1 & 0 & 1 & 0 & 0 & 1 & 01001 & 5--1 & 1 & 1 & 0 & 0 & 0 & 11000 \\
\hline 2--2 & 0 & 0 & 0 & 1 & 1 & 00011 & 5--2 & 0 & 1 & 1 & 0 & 0 & 01100 \\
\hline 2--3 & 0 & 0 & 0 & 1 & 1 & 00011 & $5--3$ & 0 & 1 & 1 & 0 & 0 & 01100 \\
\hline 2--4 & 0 & 1 & 0 & 1 & 1 & 01011 & $5--4$ & 0 & 0 & 1 & 0 & 0 & 00100 \\
\hline $2--5$ & 0 & 1 & 0 & 0 & 1 & 01001 & $5--5$ & 0 & 0 & 1 & 0 & 0 & 00100 \\
\hline
\end{tabular}


Table 2: Attributes of the grid after extracting the lithological information. For each cell (line) a lithological spectrum is defined by the presence/absence of each lithology on the map (columns)

\begin{tabular}{|c|c|c|c|c|c|c|c|c|c|}
\hline Cell\# & $\begin{array}{l}\text { Lithological } \\
\text { spectrum } \\
\text { ABCDE }\end{array}$ & $\mathrm{AHC} 15$ & Qual15 & $\mathrm{AHC10}$ & Qual10 & $\mathrm{AHC7}$ & Qual7 & AHC5 & Qual5 \\
\hline $0--0$ & 11000 & 11 & 0.00 & 8 & 0.00 & 6 & 0.44 & 4 & 0.44 \\
\hline $0--1$ & 11000 & 11 & 0.00 & 8 & 0.00 & 6 & 0.44 & 4 & 0.44 \\
\hline $0--2$ & 11000 & 11 & 0.00 & 8 & 0.00 & 6 & 0.44 & 4 & 0.44 \\
\hline $0--3$ & 11000 & 11 & 0.00 & 8 & 0.00 & 6 & 0.44 & 4 & 0.44 \\
\hline $0--4$ & 11000 & 11 & 0.00 & 8 & 0.00 & 6 & 0.44 & 4 & 0.44 \\
\hline $0--5$ & 10000 & 12 & 0.00 & 9 & 0.00 & 6 & 1.54 & 4 & 1.54 \\
\hline $1--0$ & 01000 & 3 & 0.00 & 3 & 1.32 & 2 & 1.32 & 1 & 2.34 \\
\hline $1--1$ & 01001 & 5 & 0.00 & 4 & 0.00 & 3 & 0.00 & 2 & 0.00 \\
\hline $1--2$ & 01001 & 5 & 0.00 & 4 & 0.00 & 3 & 0.00 & 2 & 0.00 \\
\hline $1--3$ & 01001 & 5 & 0.00 & 4 & 0.00 & 3 & 0.00 & 2 & 0.00 \\
\hline $1--4$ & 11001 & 13 & 0.00 & 10 & 1.48 & 7 & 1.48 & 5 & 1.48 \\
\hline $1--5$ & 11000 & 11 & 0.00 & 8 & 0.00 & 6 & 0.44 & 4 & 0.44 \\
\hline 2--0 & 01001 & 5 & 0.00 & 4 & 0.00 & 3 & 0.00 & 2 & 0.00 \\
\hline $2--1$ & 01001 & 5 & 0.00 & 4 & 0.00 & 3 & 0.00 & 2 & 0.00 \\
\hline $2--2$ & 00011 & 8 & 0.00 & 6 & 0.00 & 4 & 1.11 & 3 & 1.42 \\
\hline $2--3$ & 00011 & 8 & 0.00 & 6 & 0.00 & 4 & 1.11 & 3 & 1.42 \\
\hline $2--4$ & 01011 & 7 & 0.00 & 5 & 0.99 & 4 & 1.11 & 3 & 2.00 \\
\hline $2--5$ & 01001 & 5 & 0.00 & 4 & 0.00 & 3 & 0.00 & 2 & 0.00 \\
\hline $3--0$ & 00101 & 1 & 0.00 & 1 & 0.00 & 1 & 1.13 & 1 & 1.52 \\
\hline $3--1$ & 00101 & 1 & 0.00 & 1 & 0.00 & 1 & 1.13 & 1 & 1.52 \\
\hline $3--2$ & 00111 & 10 & 0.00 & 7 & 0.99 & 5 & 0.99 & 3 & 1.02 \\
\hline $3--3$ & 00110 & 9 & 0.00 & 7 & 0.99 & 5 & 0.99 & 3 & 1.73 \\
\hline $3--4$ & 00111 & 10 & 0.00 & 7 & 0.99 & 5 & 0.99 & 3 & 1.02 \\
\hline $3--5$ & 00101 & 1 & 0.00 & 1 & 0.00 & 1 & 1.13 & 1 & 1.52 \\
\hline 4--0 & $\quad 10101$ & 14 & 0.00 & 10 & 1.48 & 7 & 1.48 & 5 & 1.48 \\
\hline $4--1$ & 11101 & 15 & 0.00 & 10 & 0.94 & 7 & 0.94 & 5 & 0.94 \\
\hline 4--2 & 01111 & 6 & 0.00 & 5 & 0.99 & 4 & 1.79 & 3 & 1.74 \\
\hline $4--3$ & 00110 & 9 & 0.00 & 7 & 0.99 & 5 & 0.99 & 3 & 1.73 \\
\hline $4--4$ & 00100 & 2 & 0.00 & 2 & 0.00 & 1 & 0.85 & 1 & 0.86 \\
\hline $4--5$ & 00100 & 2 & 0.00 & 2 & 0.00 & 1 & 0.85 & 1 & 0.86 \\
\hline $5--0$ & 10000 & 12 & 0.00 & 9 & 0.00 & 6 & 1.54 & 4 & 1.54 \\
\hline $5--1$ & 11000 & 11 & 0.00 & 8 & 0.00 & 6 & 0.44 & 4 & 0.44 \\
\hline 5--2 & 01100 & 4 & 0.00 & 3 & 0.66 & 2 & 0.66 & 1 & 1.52 \\
\hline $5--3$ & 01100 & 4 & 0.00 & 3 & 0.66 & 2 & 0.66 & 1 & 1.52 \\
\hline $5--4$ & 00100 & 2 & 0.00 & 2 & 0.00 & 1 & 0.85 & 1 & 0.86 \\
\hline $5--5$ & 00100 & 2 & 0.00 & 2 & 0.00 & 1 & 0.85 & 1 & 0.86 \\
\hline
\end{tabular}

Table 3: Attributes of the grid after AHC. The different AHC columns correspond to different cut-off levels in the dendrogram. Whole numbers correspond to the lithological association for a given cell and for a set cut-off level (see Figure 5). 'Qual' measures the quality of each cell in terms of the dissimilarity between it and the multivariate centre of gravity of the class comprising the cell 